\title{
Management of Dyslipidemia in Cushing's Syndrome
}

\author{
Yona Greenman \\ Institute of Endocrinology, Metabolism and Hypertension, Tel Aviv-Sourasky Medical Center, and Sackler School of \\ Medicine, Tel Aviv University, Tel Aviv, Israel
}

\section{Key Words}

Hyperlipidemia $\cdot$ Ketoconazole

\begin{abstract}
Cardiovascular risk factors such as hypertension, hyperlipidemia and glucose intolerance are highly prevalent in Cushing's syndrome. Lipid abnormalities have been reported in $40-70 \%$ of patients, including those with 'subclinical' disease. Surgical cure is associated with significant amelioration of lipid profile in the majority of patients. Treatment of persistent hyperlipidemia should be conducted according to the accepted general principles in use for other medical conditions. Nevertheless, patients requiring medical treatment for persistent hypercortisolism present specific challenges, according to the selected therapeutic agent. For example, treatment with the adrenolytic drug o,p'DDD is associated with a prominent increase in cholesterol levels that necessitates intensive use of lipid lowering agents. The use of ketoconazole, a potent inhibitor of cytochrome P450 3A4 (CYP3A4), may significantly increase plasma concentrations of certain statins (such as simvastatin and atorvastatin) that undergo metabolism by the same pathway, thus increasing the risk of complications and side effects. Therefore, preference should be given to HMG-CoA inhibitors that are me-
\end{abstract}

tabolized by different pathways, such as pravastatin. In summary, hyperlipidemia should be aggressively treated in patients with Cushing's syndrome in view of the increased cardiovascular morbidity and mortality associated with this disorder.

Copyright $\odot 2010$ S. Karger AG, Basel

\section{Introduction}

Cushing's syndrome is associated with increased morbidity and mortality. The 5 -year survival rate was reported to be $50 \%$ when effective treatment was not available [1]. Despite the significant improvement in therapeutic modalities, the standardized mortality ratio remains elevated [2]. Chronic hypercortisolism is associated with several cardiovascular risk factors, including diabetes, hypertension, visceral obesity and dyslipidemia, leading to an increased incidence of cardiovascular disease [3]. The relative risk for cardiovascular events is increased not only in endogenous Cushing's syndrome, but also as a consequence of treatment with high-dose glucocorticoids [4]. Even subclinical hypercortisolism [5] as well as cortisol levels in the highest tertile of the normal range [6] were associated with increased cardiovascular risk.

\section{KARGER \\ Fax +41613061234 E-Mail karger@karger.ch} www.karger.com (c) 2010 S. Karger AG, Basel 0028-3835/10/0925-0091\$26.00/0

Accessible online at:

www.karger.com/nen
Yona Greenman

Institute of Endocrinology, Metabolism and Hypertension

Tel Aviv-Sourasky Medical Center

6 Weizmann Street, IL-64239 Tel Aviv (Israel)

Tel. +972 3697 3899, Fax +972 3697 4578, E-Mail greenman@ tasmc.health.gov.il 
Table 1. Prevalence of hyperlipidemia in Cushing's syndrome in relation to the cut-offs used for establishing the diagnosis

\begin{tabular}{lcclll}
\hline \multirow{2}{*}{ Series } & \multicolumn{2}{l}{ High total cholesterol, mg/dl } & & \multicolumn{2}{l}{ High triglycerides, mg/dl } \\
\cline { 2 - 2 } & patients (\%) & cut-off & & patients (\%) & cut-off \\
\hline Colao et al. [12] & $4 / 15(26.7)$ & $>240$ & & $1 / 15(6.7)$ & $>250$ \\
Faggiano et al. [13] & $13 / 25(52)$ & $>240$ & & $5 / 25(20)$ & $>250$ \\
Mancini et al. [14] & $12 / 49(25)$ & $>250$ & & $6 / 49(12.5)$ & $>250$ \\
Tauchmanovà et al. [5]* & $10 / 28(35)$ & $>200$ & & $10 / 28(35)$ & $>160$ \\
\hline
\end{tabular}

* Patients with subclinical Cushing's syndrome.

\section{Dyslipidemia in Cushing's Syndrome}

The effects of glucocorticoids on lipid metabolism are complex. Cortisol increases whole body lypolysis, but chronic hypercortisolemia results in increased fat mass [7]. On the one hand, glucocorticoids induce hormonesensitive lipase activity in adipose tissue, augmenting intra-adipocyte triglyceride hydrolysis. On the other hand, hypercortisolemia stimulates lipoprotein lipase activity, which is further potentiated by hyperinsulinemia, leading to intravascular lipolysis and increased uptake of nonesterified fatty acids and glycerol in adipose tissue [8]. It has recently been shown that glucocorticoids inhibit AMP-activated protein kinase activity in adipose tissue, suggesting an additional mechanism to explain the deposition of visceral adipose tissue and the consequent central obesity observed in patients with hypercortisolemia [9]. The dyslipidemia in Cushing's syndrome is characterized by increased plasma levels of total cholesterol, LDL and VLDL cholesterol, and triglycerides [10]. Interestingly, patients who developed characteristic steroidinduced fat deposition (dorsocervical, facial, supraclavicular) during prolonged high-dose glucocorticoid treatment had higher total- and lower HDL-cholesterol levels than those who did not develop these morphological changes [11].

It is difficult to state the true prevalence of hyperlipidemia in patients with Cushing's syndrome, as cut-offs used to establish the diagnosis vary among different studies. Furthermore, most published series used criteria recommended in older guidelines such as the National Cholesterol Education Program (NCEP) Expert Panel on Detection, Evaluation, and Treatment of High Blood Cholesterol in Adults (Adult Treatment Panel II) [12, 13] or the World Health Organization-International Society of Hypertension (WHO/ISH) 1999 guidelines [14]. Total cholesterol is reported to be elevated in $25-52 \%$ of patients, whereas high serum triglycerides were found in $7-35 \%$ of patients (table 1). Reduced HDL-cholesterol levels were reported in $14.2 \%$ [14] to $36 \%$ [13] of patients. If current criteria were used, the rates of hyperlipidemia would probably be higher.

Is this prevalence higher than that found in the general population? The answer to this question is not simple, with inconsistent reports in the literature. Several factors may contribute to the discrepant results. Cushing's patient series are usually small, thus decreasing the statistical power for comparisons. Another important factor is whether the reference population to which patients' parameters were compared has been matched for BMI. Faggiano et al. [13] found that total and LDL-cholesterol levels were higher and that HDL-cholesterol levels were lower in patients compared to a group of healthy subjects. Nevertheless, when the same group of patients was compared to a group of BMI-matched controls, the only remaining difference was that HDL-cholesterol levels were lower in the patients' population, resulting in a significant higher cholesterol/HDL-cholesterol ratio (table 2). There were no differences in triglyceride levels among all groups. In contrast, Terzolo et al. [15] found higher triglyceride levels in patients with Cushing's disease in comparison to healthy controls (not matched for BMI) but there were no differences in cholesterol levels. Finally, total cholesterol, LDL cholesterol and triglycerides were higher, and HDL cholesterol was lower in patients with subclinical Cushing's syndrome in comparison to BMI-matched controls [5]. 
Table 2. Lipid parameters in patients with Cushing's disease at diagnosis and 1 year after remission, compared to healthy controls (control group 1) and to BMI-matched controls (control group 2): adapted from Faggiano et al. [13]

\begin{tabular}{|c|c|c|c|c|}
\hline & \multicolumn{2}{|l|}{ Patients } & \multirow{2}{*}{$\begin{array}{l}\text { Control } 1 \text { (sex } \\
\text { and age matched) }\end{array}$} & \multirow{2}{*}{$\begin{array}{l}\text { Control } 2 \\
\text { (BMI matched) }\end{array}$} \\
\hline & active disease & 1 year remission & & \\
\hline Number & 25 & 25 & 32 & 32 \\
\hline BMI & $29.2 \pm 1.8$ & $26.8 \pm 1.5$ & $22.8 \pm 1.6$ & $28.4 \pm 1.8$ \\
\hline Triglycerides, mg/dl & $172 \pm 35$ & $159 \pm 26$ & $134 \pm 26$ & $182 \pm 35$ \\
\hline Total cholesterol, mg/dl & $240 \pm 25^{\mathrm{a}}$ & $213 \pm 23$ & $174 \pm 15$ & $219 \pm 19$ \\
\hline LDL cholesterol, mg/dl & $168 \pm 23^{c, d}$ & $145 \pm 19^{\mathrm{a}}$ & $103 \pm 11$ & $149 \pm 15$ \\
\hline HDL cholesterol, mg/dl & $38 \pm 3^{b, c}$ & $43 \pm 3.5^{c}$ & $55 \pm 2.3$ & $50 \pm 2.7$ \\
\hline Total/HDL-cholesterol ratio & $6.1 \pm 0.6^{b, c}$ & $5.1 \pm 0.5^{c}$ & $3.1 \pm 0.3$ & $4.3 \pm 0.4$ \\
\hline
\end{tabular}

${ }^{\mathrm{a}} \mathrm{p}<0.05$ vs. control $1 ;{ }^{\mathrm{b}} \mathrm{p}<0.05$ vs. control $2 ;{ }^{\mathrm{c}} \mathrm{p}<0.01$ vs. control $1 ;{ }^{\mathrm{d}} \mathrm{p}<0.05$ vs. remission.

\section{Does Correction of Hypercortisolism Improve Dyslipidemia?}

Most series report an improvement in hyperlipidemia with correction of hypercortisolemia, although a complete normalization of lipid parameters is usually not achieved. In a longitudinal study, 25 patients were evaluated at baseline and 1 year following remission or medical control of Cushing's disease. A significant decrease in LDL-cholesterol levels was observed, but levels remained higher than in healthy controls [13] (table 2). Similarly, in a cross-sectional study performed 5 years after cure or control of pituitary Cushing's disease, levels of total and LDL cholesterol were similar to the levels found in BMImatched controls but higher than in normal controls. HDL cholesterol remained significantly lower in comparison to both control groups [12]. Correction of Cushing's syndrome after excision of adrenal adenomas led to a decrease in total cholesterol levels and in the total/HDLcholesterol ratio [16]. No changes in lipid parameters were observed in patients operated for subclinical Cushing's syndrome reported by the same investigators. In contrast, in a prospective randomized study, $37.5 \%$ of patients who underwent excision of adrenal adenoma causing subclinical hypercortisolism had an improvement in lipid levels, whereas no improvement was observed in the conservatively treated arm [17]. Finally, Danilowicz et al. [18] showed that correction of cortisol overreplacement in patients with hypopituitarism caused a significant reduction in body weight, as well as cholesterol and triglyceride concentrations.

\section{Management of Dyslipidemia in Cushing's Syndrome}

There are no studies or guidelines as to how hyperlipidemia in Cushing's syndrome should be managed. As has been already mentioned, hypercortisolism is often associated with several cardiovascular risk factors. Therefore, quantification of cardiovascular risk is important to guide the intensiveness of treatment in the individual patient. A carefully conducted study calculated the global cardiovascular risk in a series of 49 patients with Cushing's syndrome. The estimated risk was calculated considering the combined effect of hypertension, diabetes, hyperlipidemia, family history of cardiovascular disease at an early age, present or past history of ischemic heart disease, cerebrovascular and peripheral vascular disease, life style factors, such as smoking and physical activity, and evaluation of target organ damage such as left ventricular hypertrophy, retinopathy, atherosclerotic plaques and proteinuria. Eighty percent of this cohort was classified as having a high or very high cardiovascular risk, according to the $1999 \mathrm{WHO} / \mathrm{ISH}$ guidelines [14]. Based on this premise, aggressive treatment of cardiovascular risk factors according to standard practice should be recommended for the majority of these patients. This policy should be adopted not only during the phase of active disease, but also in the long term, as it has been shown that even five years after disease remission the high rates of cardiovascular risk factors persisted [12]. 


\section{Special Considerations}

\section{Effects of Pharmacological Therapy of}

Hypercortisolism on Lipid Levels

\section{Ketoconazole}

Ketoconazole is the most widely used drug in the pharmacotherapy of Cushing's syndrome. It is an antifungal imidazole derivative that blocks several steps in cortisol biosynthesis, particularly through inhibition of C17,20 lyase and $17 \alpha$-hydroxylase activities [19]. Ketoconazole is also an inhibitor of cholesterol biosynthesis, acting directly by blocking the conversion of methyl sterols to cholesterol and indirectly by suppressing cholesterol synthesis via feedback inhibition of HMG-CoA reductase by sterol intermediates [20]. It has been used to treat patients with familial hypercholesterolemia before the widespread use of HMG-CoA reductase inhibitors, reducing total, intermediate density and LDL cholesterol, as well as apoB levels by approximately $25 \%[20,21]$. Hence, the use of ketoconazole for the control of hypercortisolism may have a beneficial effect on lipid control.

\section{Mitotane}

Mitotane or o,p'-DDD is a DDT derivative used mainly for the treatment of adrenal carcinoma or cases of intractable Cushing's disease $[22,23]$. It induces mitochondrial degeneration resulting in adrenocortical atrophy and necrosis. Additionally, it inhibits steroidogenesis by reducing cholesterol side-chain cleavage and $11 \beta$-hydroxylation [19]. However, mitotane uniformly raises circulating cholesterol levels by reducing hepatic production of oxysterols, thus leading to increased levels of HMG-CoA reductase [24]. Maximal changes in cholesterol levels occur 1-5 months after drug initiation. Mitotane increases total serum cholesterol levels by $68 \%$, with significant elevations in LDL cholesterol and apoB, but no changes in triglycerides, HDL-cholesterol, apoA-1 or
Lp(a) levels [24]. This effect was successfully reversed by treatment with simvastatin [24]. The deleterious effect of mitotane on lipid levels should be recognized and promptly treated.

Drug Interactions between Lipid-Lowering Drugs and Steroid Biosynthesis Inhibitors

Ketoconazole interferes with the metabolism of many drugs via the inhibition of several hepatic $\mathrm{P} 450$ enzymes, e.g. CYP3A4, CYP2C9, CYP1A2. Simvastatin, lovastatin and atorvastatin are metabolized by cytochrome $\mathrm{P} 450$ CYP3A4, therefore their plasma concentrations and the risk of myotoxicity are greatly increased by the concomitant use of ketoconazole. In this clinical situation, pravastatin and rosuvastatin are preferable, as they are excreted mainly unchanged and their plasma concentrations are not significantly increased by CYP3A4 inhibitors [25].

\section{Conclusions}

In addition to the correction of hypercortisolism, strict control of cardiovascular risk factors is essential to reduce the high rates of cardiovascular morbidity and mortality associated with Cushing's syndrome. In this context, hyperlipidemia should be aggressively treated according to general clinical practice, but giving special consideration to the effects that pharmacotherapy used to lower cortisol levels may have on lipid levels, as well as to possible drug interactions between steroid biosynthesis inhibitors and statins.

\section{Disclosure Statement}

Dr. Greenman has received honoraria from Novartis for her role as Chair of the Steering Committee in relation to the OASIS trial. No conflict of interest exists.
References 484 . complications of Cushing's syndrome: a consensus statement. J Clin Endocrinol Metab 2003;88:5593-5602.

ral history of Cushing's syndrome. Am J Med 1952;13:597-614.

-2 Etxabe J, Vasquez JA: Morbidity and mortality in Cushing's disease: and epidemiological approach. Clin Endocrinol 1994;40:479-

-3 Arnaldi G, Angeli A, Atkinson AB, Bertagna $\mathrm{X}$, Cavagnini F, Chrousos GP, Fava GA, Findling JW, Gaillard RC, Grossman AB, Kola B, Lacroix A, Mancini T, Mantero F, Newell-Price J, Nieman LK, Sonino N, Vance ML, Giustina A, Boscaro M: Diagnosis and
4 Wei L, MacDonald TM, Walker BR: Taking glucocorticoids by prescription is associated with subsequent cardiovascular disease. Ann Intern Med 2004;141:764-770.

-5 Tauchmanovà L, Rossi R, Biondi B, Pulcrano M, Nuzzo V, Palmieri EA, Fazio S, Lombardi G: Patients with subclinical Cushing's syndrome due to adrenal adenoma have increased cardiovascular risk. J Clin Endocrinol Metab 2002;87:4872-4878. 
-6 Dekker MJ, Koper JW, van Aken MO, Pols HA, Hofman A, de Jong FH, Kirschbaum C, Witteman JC, Lamberts SW, Tiemeier $\mathrm{H}$ : Salivary cortisol is related to atherosclerosis of carotid arteries. J Clin Endocrinol Metab 2008;93:3741-3747.

7 Samra JS, Clark ML, Humphreys SM, MacDonald IA, Bannister PA, Frayn KN: Effects of physiological hypercortisolemia on the regulation of lipolysis in subcutaneous adipose tissue. J Clin Endocrinol Metab 1998; 83:626-631

$\checkmark 8$ van Raalte DH, Ouwens DM, Diamant M: Novel insights into glucocorticoid-mediated diabetogenic effects: towards expansion of therapeutic options? Eur J Clin Invest 2009; 39:81-93.

-9 Kola B, Christ-Crain M, Lolli F, Arnaldi G, Giacchetti G, Boscaro M, Grossman AB, Korbonits M: Changes in adenosine 5'monophosphate-activated protein kinase as a mechanism of visceral obesity in Cushing's syndrome. J Clin Endocrinol Metab 2008;93: 4969-4973.

>10 Taskinen MR, Nikkilä EA, Pelkonen R, Sane T: Plasma lipoproteins, lipolytic enzymes, and very low density lipoprotein triglyceride turnover in Cushing's syndrome. J Clin Endocrinol Metab 1983;57:619-626.

- 11 Fardet L, Cabane J, Kettaneh A, Lebbé C, Flahault A: Corticosteroid-induced lipodystrophy is associated with features of the metabolic syndrome. Rheumatology 2007;46: 1102-1106.
12 Colao A, Pivonello R, Spiezia S, Faggiano A, Ferone D, Filippella M, Marzullo P, Cerbone G, Siciliani M, Lombardi G: Persistence of increased cardiovascular risk in patients with Cushing's disease after five years of successful cure. J Clin Endocrinol Metab 1999; 84:2664-2672.

13 Faggiano A, Pivonello R, Spiezia S, De Martino MC, Filippella M, Di Somma C, Lombardi G, Colao A: Cardiovascular risk factors and common carotid artery caliber and stiffness in patients with Cushing's disease during active disease and 1 year after disease remission. J Clin Endocrinol Metab 2003;88: 2527-2533.

14 Mancini T, Kola B, Mantero F, Boscaro M, Arnaldi G: High cardiovascular risk in patients with Cushing's syndrome according to 1999 WHO/ISH guidelines. Clin Endocrinol 2004;61:768-777.

15 Terzolo M, Allasino B, Bosio S, Brusa E, Daffara F, Ventura M, Aroasio E, Sacchetto G Reimondo G, Angeli A, Camaschella C: Hyperhomocysteinemia in patients with Cushing's syndrome. J Clin Endocrinol Metab 2004;89:3745-3751.

16 Erbil Y, Ademoğlu E, Ozbey N, Barbaros U, Yanik BT, Salmaslioğlu A, Bozbora A, Ozarmağan S: Evaluation of the cardiovascular risk in patients with subclinical Cushing syndrome before and after surgery. World J Surg 2006;30:1665-1671

17 Toniato A, Merante-Boschin I, Opocher G, Pelizzo MR, Schiavi F, Ballotta E: Surgical versus conservative management for subclinical Cushing syndrome in adrenal incidentalomas: a prospective randomized study. Ann Surg 2009;249:388-391.

-18 Danilowicz K, Bruno OD, Manavela M, Gomez RM, Barkan A: Correction of cortisol overreplacement ameliorates morbidities in patients with hypopituitarism: a pilot study. Pituitary 2008;11:279-285.
19 Igaz P, Tömböl Z, Szabó PM, Likó I, Rácz K: Steroid biosynthesis inhibitors in the therapy of hypercortisolism: theory and practice. Curr Med Chem 2008;15:2734-2747.

20 Gylling H, Vanhanen H, Miettinen TA: Effects of ketoconazole on cholesterol precursors and low density lipoprotein kinetics in hypercholesterolemia. J Lipid Res 1993;34: 59-67.

21 Gylling H, Vanhanen H, Miettinen TA: Hypolipidemic effect and mechanism of ketoconazole without and with cholestyramine in familial hypercholesterolemia. Metabolism 1991;40:35-41.

-22 Terzolo M, Pia A, Berruti A, Osella G, Alì A, Carbone V, Testa E, Dogliotti L, Angeli A: Low-dose monitored mitotane treatment achieves the therapeutic range with manageable side effects in patients with adrenocortical cancer. J Clin Endocrinol Metab 2000;85: 2234-2238.

-23 Kawai S, Ichikawa Y, Kaburaki J, Yoshida T: 18 years mitotane therapy for intractable Cushing's disease. Lancet 1999;354:951.

24 Maher VM, Trainer PJ, Scoppola A, Anderson JV, Thompson GR, Besser GM: Possible mechanism and treatment of o,p'DDD-induced hypercholesterolaemia. Q J Med 1992; 84:671-679

25 Neuvonen PJ, Niemi M, Backman JT: Drug interactions with lipid-lowering drugs: mechanisms and clinical relevance. Clin Pharmacol Ther 2006;80:565-581. 